\title{
Avaliação de padrões físico-químicos e microbiológicos do leite em diferentes fases de lactação nas estações do ano em granjas leiteiras no Estado do Paraná - Brasil
}

\author{
Evaluation of the milk physicochemical and microbiological \\ patterns in different lactation phases in year seasons in milk farms \\ of Paraná State - Brazil
}

\author{
Eder Paulo Fagan ${ }^{1 *}$; Ronaldo Tamanini²; Rafael Fagnani²; Vanerli Beloti²; \\ Márcia de Aguiar F. Barros ${ }^{3}$; Clóves Cabreira Jobim ${ }^{4}$
}

\section{Resumo}

\begin{abstract}
O objetivo deste estudo foi avaliar os parâmetros físico-químicos e microbiológicos do leite em diferentes fases de lactação, durante as estações do ano em duas granjas leiteiras produtoras de leite tipo A (Granja 1 (G1) e Granja 2 (G2)), no período de janeiro de 2004 a janeiro de 2005. Foram colhidas e analisadas 320 amostras de leite cru para análise da acidez Dornic, California Mastitis Test (CMT), Contagem de Células Somáticas (CCS) e crioscopia. Para as análises estatísticas dos dados, foram empregados os Modelos Lineares Generalizados (GLM). Constatou-se que os resultados das análises estatísticas não foram significativos ( $\mathrm{P}>0,05)$, durante as estações do ano, nas diferentes fases de lactação, entre as granjas avaliadas. Os resultados médios para CCS $(935.000 \mathrm{CCS} / \mathrm{mL})$, estão em desacordo com a legislação vigente. Com relação à acidez Dornic e Crioscopia, os valores não excederam o limite exigido pela IN51. Os resultados das contagens médias de aeróbios mesófilos no outono na G2 e na primavera na G1 mostraram-se em desacordo com a IN51. No caso dos Coliformes totais e Escherichia coli, observou-se que os resultados médios foram maiores na G1, em todas as estações do ano. Evidenciou-se que as qualidades físico-químicas e microbiológicas estão principalmente ligadas às práticas de manejo durante a ordenha.
\end{abstract}

Palavras-chave: Acidez Dornic, CCS, crioscopia, microbiologia

\begin{abstract}
The objective of this study was to evaluate the physicochemical and microbiological parameters of milk in different lactation phases during a year in two Dairy farms producing type A milk (Brazilian Standards) and classified as Farm 1 (G1) and Farm 2 (G2). The 320 raw milk samples were collected to analyze acidity Dornic, California Mastit Test (CMT), Somatic Cells Counting (SCC) and Cryoscopy $(0 \mathrm{H})$ during four seasons, in the period of January 2004 to January 2005. To data statistical analyses a General linear model (GLM) was used. The CMT, the SCC, acidity Dornic and Cryoscopy (OH) results were not significant $(\mathrm{P}>0.05)$, during the year seasons, between the farms and in the different lactation phases. The SCC $(935.000$ cells $/ \mathrm{mL})$ average results are in disagreement with the legislation. To the Dornic acidity and Cryoscopy $\left({ }^{\circ} \mathrm{H}\right)$, the values had not exceeded the limit demanded by IN51. The results of mesophilic aerobic organisms counting during autumn (G2) and during spring (G1) had

Chefe do Departamento de Veterinária e Produção Animal - DVPA FALM/UENP, Bandeirantes PR E-mail: fagan@ffalm.br

Programa de Pós Graduação em Ciência Animal (Sanidade Animal) da Universidade Estadual de Londrina, Londrina PR.

Faculdade de Agronomia e Medicina Veterinária, Universidade de Brasília, Brasília, DF.

Professor Orientador, Pesquisador do Departamento de Zootecnia, Universidade Estadual de Maringá , Maringá PR

Autor para correspondência
\end{abstract}


revealed a disagreement with IN51. High levels of coliforms (TC) and Escherichia coli (EC) were observed in G1 in all seasons when compared with G2. It was demonstrated that the physical-chemistry and microbiological quality are important to handling practical during milks.

Key words: Acidity Dornic, SCC, cryoscopy, microbiology

\section{Introdução}

O leite é considerado um alimento muito nutritivo e de fácil assimilação. Por esta razão, torna-se um alimento adequado para o homem e também um bom meio de cultura para a maioria dos microrganismos (SILVEIRA; SAKUMA; DUARTE, 1989; BRANDÃO, 1999). O manejo higiênico sanitário nas propriedades leiteiras, as estações do ano, o estresse dos animais e a fase de lactação são fatores que podem alterar a qualidade do leite. Neste sentido, a Contagem de Células Somáticas (CCS), os parâmetros físico-químicos e microbiológicos do leite têm sido ferramentas importantes na avaliação da qualidade do leite pelos órgãos governamentais e pela indústria leiteira.

A qualidade do leite é determinada pelo sabor, inocuidade, integridade e valor nutritivo. De acordo com Wolter (1997), a qualidade é um termo vasto que abrange a segurança sanitária e o valor nutricional. Por isso, a maioria dos países onde a cadeia produtiva está bem estruturada baseia a remuneração do leite em sua composição química e microbiológica.

Segundo Martins et al. (2004), os mercados nacionais e internacionais são, sem dúvida, o fator motivador geral que estimula o Brasil a discutir pagamento por qualidade. O leite é fonte alimentar de proteínas de alto valor biológico, vitaminas e minerais, porém a sua composição química o torna um alimento altamente perecível e as suas características físicas, químicas e biológicas são facilmente alteradas pela manipulação, presença de células somáticas e ação de microrganismos. Os parâmetros físico-químicos do leite podem ser alterados em função de alguns fatores nutricionais, ambientais (SANTOS; XAVIER; PASSOS, 1981), fraudes do produto (PADILHA; FERNADEZ, 1999), dentre outros. Bramley e Mckinnon (1990);
Cerqueira et al. (1994) e Soler, De Paz e Nuñez (1995) relatam que os fatores como deficiências no manejo e higiene de ordenha, índices elevados de mastite, manutenção e desinfecção inadequadas dos equipamentos, refrigeração ineficiente ou inexistente e mão-de-obra desqualificada contribuem para a má qualidade do leite cru.

A mastite bovina tem se apresentado como a principal doença causadora de prejuízos na bovinocultura de leite, em função do decréscimo na produção (MILLER et al., 1993) e alterações na composição do leite (PAAPE; CAPUCO; GUIDRY, 1995), freqüentemente aliadas ao comprometimento da qualidade da matéria-prima (BRAMLEY et al., 1996). Dentre os métodos laboratoriais recomendados para diagnosticar a incidência de mastite, pode-se indicar a Coadura do leite, Califórnia Mastite teste (CMT) e a CCS (FONSECA; SANTOS, 2000). A produção de leite com altas CCS afetam a composição e o tempo de vida de prateleira dos derivados, proporcionando grandes prejuízos para a indústria de laticínios devido à redução na síntese de proteínas (caseína). Sabe-se também que, em animais com inflamação da glândula mamária, o teor de gordura e a lactose também sofrem diminuição, em torno de 10\% (FONSECA; SANTOS, 2000).

De acordo com o Regulamento Técnico de Identidade e Qualidade do Leite Cru Refrigerado da IN 51 (BRASIL, 2002), já implantada desde junho de 2005, o leite cru refrigerado deverá atender a CCS e os requisitos físico-químicos de: gordura, densidade relativa, acidez titulável, extrato seco desengordurado, índice crioscópico e proteína. Segundo Mattos e Pedroso (2005), os valores exigidos pela IN 51 são os mínimos aceitáveis para melhoria da matéria-prima. À medida que os laticínios passarem a remunerar o produtor pela 
qualidade os valores exigidos pela legislação serão gradativamente alterados para melhorar a qualidade do leite.

Este trabalho teve como objetivo avaliar os parâmetros físico-químicos e microbiológicos do leite produzido por vacas em diferentes fases de lactação, durante as estações do ano em duas granjas leiteiras no Estado do Paraná.

\section{Material e Métodos}

$\mathrm{O}$ experimento foi realizado em duas granjas leiteiras produtoras de leite tipo A, localizadas nos municípios de Londrina e Leópolis, Estado do Paraná, no período de janeiro de 2004 a janeiro de 2005. A região é caracterizada como de clima subtropical, com temperaturas médias de $23,23^{\circ} \mathrm{C}$ no verão e de $19,93^{\circ} \mathrm{C}$ no inverno. Inicialmente, foram obtidas informações sobre o sistema de alimentação, manejo de ordenha, tipo de identificação, raça ou grau de sangue, média de produção, manejo reprodutivo, controle sanitário e sistema de beneficiamento do leite, bem como outros dados definidos no questionário de acompanhamento das propriedades.

As granjas foram identificadas como Granja 1 (G1), localizada no município de Leópolis, e Granja 2 (G2), situada no município de Londrina.

$\mathrm{Na}$ G1, o rebanho era composto por vacas puras da raça holandesa, multíparas, brincadas, com aproximadamente 160 animais em lactação, peso médio de $650 \mathrm{~kg}$ e produção média por animal de $29,5 \mathrm{~kg}$ de leite/vaca/dia, em duas ordenhas. As vacas eram mantidas confinadas em sistema 'Free-stalls', amplo, ventilado, inclinado e com antiderrapantes. Esta granja apresentava sala de ordenha tipo espinha de peixe e sistema de limpeza dos equipamentos automatizado e ainda utilizavamse medidas de controle de mastite, tais como: descarte dos três primeiros jatos, caneca do fundo preto, 'pré-dipping' com Dermisan (Diaminopropil laurilamina a 30\%) e 'pós-dipping' com solução de iodo $(0,5 \%)$, descarte do leite de mastítico de vacas tratadas com antibiótico. A dieta era composta basicamente de alimentação volumosa (silagem de milho) e de concentrado formulado na fazenda (adicionado de caroço de algodão). A ração era fornecida em 3 frações: no período matutino (5 horas), em quantidade dobrada, no período vespertino (14 horas) e no período noturno (20 horas). A silagem era distribuída juntamente com o concentrado, de acordo com a produção e fase de lactação (Apêndice B). Os animais foram divididos em quatro grupos de acordo com a produção, sendo denominados respectivamente de grupo desafio, azul, vermelho, e novilhas primíparas e vacas em final de lactação.

A G2 era constituída de vacas da raça holandesa, com média de 30 animais em lactação, peso médio de $600 \mathrm{Kg}$ e produção média por animal, em duas ordenhas, de $16 \mathrm{~kg}$ de leite/vaca/dia. As vacas eram mantidas confinadas em sistema 'Free-stalls', onde recebia volumoso (silagem de milho) e o concentrado formulado na fazenda (adicionado de caroço de algodão). Esta granja apresentava sala de ordenha tipo espinha de peixe, sistema de limpeza dos equipamentos automatizado e utilizavam-se medidas de controle de mastite, tais como: descarte dos três primeiros jatos, caneca de fundo preto, 'pré-dipping' com imersão em hipoclorito de sódio, secagem, 'pós-dipping' com solução hipoclorito de sódio e descarte do leite mastítico de vacas tratadas com antibiótico. A distribuição dos alimentos era realizada no período matutino, às 8 horas e no vespertino, às 17 horas, sendo a silagem oferecida juntamente com o concentrado para todos os animais em lactação.

Neste estudo, foram definidas como tratamento as quatro estações do ano e os dois sistemas de produção leiteira (G1 e G2). Foram avaliados 20 animais por granja em oito colheitas, durante as quatro estações, sendo estes separados em grupos por fase de lactação (primeira fase: de zero a 90 dias; segunda fase: de 91 a 150 dias; terceira fase; de 151 a 210 dias; quarta fase: de 211 a 270 dias e quinta fase: acima de 270 dias). Na G1, os animais eram provenientes 
do grupo-desafio (animais com maior produção de leite/dia). Durante o período de avaliação, foram amostrados em cada sistema os alimentos volumosos e os concentrados, administrados aos animais em lactação. Também foram coletadas amostras do leite individual de cada animal.

O monitoramento do rebanho nas granjas foi realizado registrando-se qualquer mudança no manejo de ordenha e/ou alimentar. Durante as colheitas, anotava-se o número, fase de lactação e a produção diária de leite por animal.

\section{Colheita e Análises das Amostras}

As amostras de leite foram colhidas durante as quatro estações, nas duas granjas leiteiras. Após as medidas de controle de mastites e antes de cada ordenha, colheu-se, assepticamente, o leite diretamente dos tetos, totalizando 320 amostras em frascos estéreis de $250 \mathrm{~mL}$, que foram acondicionadas, mantidas sob refrigeração em caixas isotérmicas e enviadas para o Laboratório de Inspeção de Produtos de Origem Animal (LIPOA), da Universidade Estadual de Londrina.

Realizou-se o Califórnia Mastitis Test (CMT) para detecção de mastite subclínica do leite proveniente dos quatro quartos, utilizando a técnica Philpot e Nikerson (1991). A acidez do leite cru foi determinada pelo método Dornic (BRASIL, 1981; TRONCO, 2003), e o índice crioscópico em crioscópio eletrônico digital microprocessado (M90/BR - Laktron). Durante a ordenha, também foram colhidas amostras individualizadas de aproximadamente $40 \mathrm{~mL}$ de leite em frasco plásticos, contendo conservante (dicromato de potássio na concentração de $155 \mathrm{mg}$ por pastilha), encaminhada ao Laboratório do Programa de Análises do Leite da Associação Paranaense de Criadores Bovinos da Raça Holandesa (APCBRH), Curitiba - PR, para determinação de CCS. Especificamente, os valores médios qualitativos dos indicativos de sanidade da glândula mamária pelas análises de CMT e CCS foram expressos por valores numéricos codificados.
As análises microbiológicas realizadas foram contagem de aeróbios mesófilos em agar padrão (BRASIL, 1991-1992), e contagem de Coliformes totais e de Echerichia coli utilizando o sistema Petrifilm TM, conforme instruções do fabricante, e os resultados foram expressos em Unidades Formadoras de Colônias (UFC) por mL.

Em análises preliminares, os dados foram submetidos ao teste de Lilliefors que indicou não normalidade. Assim, as análises estatísticas foram procedidas utilizando a metodologia de Modelos Lineares Generalizados (GLM), como proposto por Nelder e Wedderburn (1972). Para tanto, utilizou-se o software GLIM 4.0.

Para as variáveis Dornic, CMT e CCS, foi admitida a distribuição de Poisson, com função de ligação logarítmica, enquanto que para a crioscopia admitiu-se a distribuição Gamma com função de ligação recíproca. No modelo estatístico, foram considerados os efeitos de granja, fase de lactação e estações para avaliar a qualidade físico-química e microbiológica do leite.

$\mathrm{Y}_{\mathrm{ijkl}}=\mu+\mathrm{Gi}+\mathrm{L}_{\mathrm{j}}+\mathrm{E}_{\mathrm{k}}+\mathrm{C}_{\mathrm{l}} / \mathrm{E}_{\mathrm{k}}+\mathrm{GL}_{\mathrm{ij}}+\mathrm{GE}_{\mathrm{ik}}+\mathrm{LE}_{\mathrm{jk}}+\mathrm{e}_{\mathrm{ijkl}}$ Em que:

$\mathrm{Y}_{\mathrm{ijkl}}=$ variáveis dependentes das qualidades físicoquímicas e microbiológicas do leite: granja i, fases de lactação j, estações do ano k e coletas 1 .

$\mu=$ constante geral

$\mathrm{Gi}=$ efeito da granja $\mathrm{i}, \mathrm{i}=1,2$;

$L_{j}=$ efeito das fases de lactação $j, j=1,2,3,4,5$;

$\mathrm{E}_{\mathrm{k}}=$ efeito estações do ano $\mathrm{k}, \mathrm{k}=1,2,3,4$;

$\mathrm{C}_{1} / \mathrm{E}_{\mathrm{k}}=$ coleta dentro das estações

$\mathrm{GL}_{\mathrm{ij}}=$ efeito da interação entre a granja i e fases de lactação j;

$\mathrm{GE}_{\mathrm{ik}}=$ efeito da interação granja i e estações do ano k; $\mathrm{LE}_{\mathrm{jk}}=$ interação das fases de lactação j e estações do ano k; e

$\mathrm{e}_{\mathrm{ijk} \mathrm{k}}=$ erros aleatórios associados à observação $\mathrm{Y}_{\mathrm{ijk} \mathrm{k}}$.

Após a utilização do procedimento GLM, as comparações das médias foram realizadas por intermédio teste $\mathrm{t}$ de Student em nível de 5\% de probabilidade com uso do programa Statistical Analysis System (SAS, 1992). 


\section{Resultados e Discussão}

Na Tabela 1, são apresentados os resultados para CMT, CCS, Dornic e Crioscopias durante as estações do ano, média das duas granjas. Constatou-se que, os resultados para CMT e CCS não foram significativos $(\mathrm{P}>0,05)$ entre as estações do ano, sendo que os resultados para $\operatorname{CMT}(0,45)$ e quanto à $\operatorname{CCS}(1,5)$ apresentaram-se menores no verão e os maiores na primavera, demonstrando semelhança de resultados entre as análises. Segundo Thiers (1999), existe alta correlação $(r=0,964)$ entre a contagem de células somáticas e o teste de CMT no leite de vacas.

Tabela 1. Valores médios dos resultados obtidos nas análises do leite, proveniente de duas granjas leiteiras, durante as estações do ano, no período de 2004/2005.

\begin{tabular}{lccccc}
\hline \multirow{2}{*}{ Estações do ano } & \multicolumn{5}{c}{ Médias das análises do leite } \\
\cline { 2 - 5 } & $(\mathrm{n})$ & ${ }^{1} \mathrm{CMT}$ & ${ }^{2} \mathrm{CCS}(\mathrm{mL})$ & Dornic $(\mathrm{g} . / 100 \mathrm{~mL})$ & Crioscopia $\left({ }^{0} \mathrm{H}\right)$ \\
\hline Verão & 80 & 0,450 & 1,500 & 0,171 & $-0,538$ \\
Outono & 80 & 0,737 & 1,550 & 0,173 & $-0,539$ \\
Inverno & 80 & 0,937 & 1,563 & 0,168 & $-0,542$ \\
Primavera & 80 & 1,175 & 1,588 & 0,171 & $-0,548$ \\
\hline
\end{tabular}

As médias não se diferiram pelo teste $\mathrm{t}$ de student em nível de $5 \%$

${ }^{1}$ CMT: A numeração (0) CMT negativo; (1) CMT positivo +; (2) CMT positivo ++ e (3) CMT positivo +++

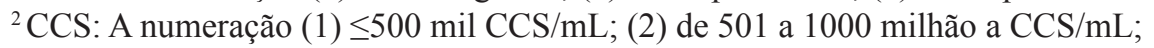

(3) de 1001 a 1500 milhões a CCS/mL e (4) $\geq 1501$ milhões CCS/mL

As variações de células somáticas presentes no leite, em ambas as granjas, estimada pelo CMT e quantificada pela $\mathrm{CCS}$, devem-se principalmente às deficiências nas práticas de manejo de ordenha e, o número e fase de lactação dos animais ordenhados. De acordo com os resultados deste trabalho, fica evidente que as variações climáticas têm pouca influência sobre a sanidade da glândula mamária e que as maiores variações observadas na primavera são provenientes de fatores ligados ao manejo de ordenha adotado nesta estação.
Os resultados apresentados na Tabela 2, para o CMT e a CCS do leite para cada granja, assim como os parâmetros físico-químicos não apresentaram diferença significativa $(\mathrm{P}>0,05)$ entre as granjas leiteiras. Os valores médios para o CMT podem ser considerados como suspeitos, enquanto que a média de CCS do leite, nas duas granjas leiteiras, foram $\geq 600.000$ células $/ \mathrm{mL}$, excedendo o limite exigido para leite cru refrigerado Tipo A, pela IN51 (BRASIL, 2002).

Tabela 2. Valores médios das propriedades físico-químicas do leite, provenientes de granja 1 (G1) e granja (G2), analisados entre o período de 2004/2005.

\begin{tabular}{lcccc}
\hline \multirow{2}{*}{ Granjas leiteiras } & \multicolumn{4}{c}{ Médias das análises físico-químicas do leite } \\
\cline { 2 - 5 } & ${ }^{I} \mathrm{CMT}$ & ${ }^{2} C C S(m L)$ & Dornic $(\mathrm{g} . / 100 \mathrm{~mL})$ & Crioscopia $\left({ }^{0} \mathrm{H}\right)$ \\
\hline $\mathrm{G} 1$ & 0,925 & 1,656 & 0,1736 & $-0,539$ \\
$\mathrm{G} 2$ & 0,725 & 1,544 & 0,1680 & $-0,544$ \\
\hline
\end{tabular}

As médias não se diferiram pelo teste $\mathrm{t}$ de student em nível de $5 \%$

${ }^{1}$ CMT - A numeração (0) CMT negativo; (1) CMT positivo +; (2) CMT positivo ++ e (3) CMT positivo +++

${ }^{2}$ CCS: A numeração (1) $\leq 500 \mathrm{mil} \mathrm{CCS/mL;} \mathrm{(2)} \mathrm{de} 501$ a 1000 milhão CCS/mL; (3) de 1001 a 1500 milhões CCS/mL e (4) $\geq 1501$ milhões $C C S / m L$. 
As médias das análises de acidez e crioscopia das duas granjas também não foram significativas $(\mathrm{P}>0,05)$ durante as estações do ano. A acidez do leite é devida principalmente pela multiplicação de microrganismos mesófilos. A acidificação do leite está associada às baixas condições de manejo higiênico sanitárias adotado durante a ordenha e acondicionamento nas granjas leiteiras. Já, o ponto de congelamento é influenciado principalmente pelas variações nos teores de lactose e de cloretos do leite. Segundo Tronco (2003), as oscilações dos componentes do leite que alteram a crioscopia podem estar associadas à fase de lactação, estação do ano, clima, alimentação, doenças dos animais, processo de pasteurização ou esterilização, estado de conservação da matéria-prima, entre outros.

Os resultados médios encontrados, em ambas as granjas, estão em desacordo com a legislação vigente. Já, a média das variáveis, acidez Dornic e crioscopia do leite apresentaram pequenas variações entre as granjas leiteiras e estão nos padrões determinados para o leite cru refrigerado Tipo A, estabelecido pela IN51. Isto revela que, o manejo higiênico dos equipamentos e os armazenamentos adotados em ambas as granjas foram admissíveis, evitando assim, a multiplicação da flora microbiana restante.
Embora os resultados médios das análises não tenham demonstrado diferença significativa a 5\%, pode-se observar que na G1, os valores para a acidez Dornic e a crioscopia do leite, foram respectivamente mais ácidos e com menor crioscopia em relação à G2. Desta forma, existem evidências de que a mastite subclínica influenciou tanto na acidez como no ponto de congelamento do leite devido à presença de acidificação microbiana e da redução de sólidos totais.

$\mathrm{Na}$ Tabela 3, são apresentados os resultados médios das duas granjas, por fase de lactação, indicativos de sanidade da glândula mamária e propriedades físico-químicas do leite, como a

Acidez Dornic e a Crioscopia. Como média das observações nas duas granjas, constatou-se que os valores apresentados não foram diferentes $(\mathrm{P}>0,05)$ entre as granjas. O resultado quantitativo da CCS multiplicado pelos valores numéricos codificados na fase final de lactação de 935.000 células $/ \mathrm{mL}$ de leite, estava acima do limite estabelecido para o leite cru refrigerado Tipo A, pela instrução IN51, que é 600.000 células/mL (BRASIL, 2002). Esta maior variação pode estar associada à sanidade da glândula mamária e a maior descamação do tecido alveolar em vacas com mais de 270 dias de lactação, que evidencia a necessidade de manejo adequado nesta fase de lactação.

Tabela 3. Valores médios das análises do leite, proveniente de duas granjas leiteiras, em diferentes fases de lactação, analisados entre o período de 2004/2005.

\begin{tabular}{lccccc}
\hline \multirow{2}{*}{ Fases de lactação } & \multicolumn{5}{c}{ Médias das análises do leite } \\
\cline { 2 - 6 } & $(\mathrm{n})$ & ${ }^{1} \mathrm{CMT}$ & ${ }^{2} C C S(m L)$ & Dornic $(\mathrm{g} . / 100 \mathrm{~mL})$ & Crioscopia $\left({ }^{0} \mathrm{H}\right)$ \\
\hline 0 a 90 dias & 89 & 0,663 & 1,640 & 0,175 & $-0,539$ \\
91 a 150 dias & 87 & 0,965 & 1,471 & 0,167 & $-0,543$ \\
151 a 210 dias & 55 & 0,872 & 1,600 & 0,167 & $-0,542$ \\
211 a 270 dias & 58 & 0,672 & 1,586 & 0,173 & $-0,542$ \\
$>$ 270 dias & 31 & 1,096 & 1,871 & 0,169 & $-0,545$ \\
\hline
\end{tabular}

As médias não se diferiram pelo teste $\mathrm{t}$ de student em nível de $5 \%$

${ }^{1} \mathrm{CMT}$ : A numeração (0) CMT negativo; (1) CMT positivo +; (2) CMT positivo ++ e (3) CMT positivo +++

${ }^{2}$ CCS: A numeração (1) $\leq 500$ mil CCS/mL; (2) de 501 a 1000 milhão CCS/mL; (3) de 1001 a 1500 milhões CCS/mL e (4) $\geq 1501$ milhões $C C S / m L$. 
As CCS do leite estão associadas a variações nas fases de lactação mesmo em vacas livres de infecção da glândulamamária sendo que esta influênciapodeocorrer tanto no início como no final da lactação. No final da lactação, observou-se aumento na CCS provavelmente devido à menor produção de leite e maior descamação do tecido epitelial da glândula mamária.

Os resultados de acidez e de crioscopia do leite (Tabela 3) não apresentaram diferenças significativas $(\mathrm{P}>0,05)$ entre as fases de lactação. Com isso, constatou-se que os valores médios obtidos em cada fase não excederam o limite exigido para leite cru refrigerado Tipo A, pela IN51, que é respectivamente de 0,14 a $0,18 \mathrm{~g} / 100 \mathrm{~mL}$, e máximo de $-0,530{ }^{0} \mathrm{H}$, para acidez Dornic, densidade e crioscopia (BRASIL, 2002).

Os valores médios da Acidez Dornic, obtidos nas estações do ano e fases de lactação dentro de cada granja leiteira não apresentaram diferenças significativas $(\mathrm{P}>0,05)$ entre os sistemas de produção das granjas. Os resultados médios encontrados nestas interações deixam evidente que os fatores, estações do ano e fases de lactação não alteram a acidez do leite ficando evidente que, a acidificação do leite está relacionada à contaminação de microrganismos inicial e as condições de armazenamento do leite.

$\mathrm{Na}$ Tabela 4, são apresentados os resultados médios do CMT, obtidos a partir da interação entre as estações do ano dentro das fases de lactação. Os valores médios obtidos para o CMT apresentaram diferença significativa $(\mathrm{P}<0,05)$ nas interações entre o outono e as fases de 91 a 150 dias e maior que 270 dias de lactação e o inverno e a fase de 151 a 210 dias de lactação. Nestas interações, constataramse as menores incidências de positividade para o CMT, que é considerado um teste subjetivo para a identificação de processos inflamatórios da glândula mamária.

Tabela 4. Valores médios do Califórnia Mastits Test (CMT), obtidos a partir da análise nas estações do ano dentro das fases de lactação, no período de 2004/2005.

\begin{tabular}{lccccc}
\hline \multirow{2}{*}{ Estações do ano } & \multicolumn{4}{c}{ Interações entre as médias do CMT } \\
\cline { 2 - 6 } & 0 a 90 dias & 91 a 150 dias & 151 a 210 dias & 211 a 270 dias & $>$ de 270 dias \\
\hline Verão & $0,4211^{\mathrm{a}}$ & $0,8333^{\mathrm{a}}$ & $1,2143^{\mathrm{a}}$ & $1,0800^{\mathrm{a}}$ & $0,9000^{\mathrm{a}}$ \\
Outono & $0,8108^{\mathrm{a}}$ & $0,6087^{\mathrm{b}}$ & $0,6250^{\mathrm{a}}$ & $0,3333^{\mathrm{a}}$ & $0,6667^{\mathrm{b}}$ \\
Inverno & $0,9545^{\mathrm{a}}$ & $0,9655^{\mathrm{a}}$ & $0,3182^{\mathrm{b}}$ & $0,2857^{\mathrm{a}}$ & 0,0000 \\
Primavera & $0,2727^{\mathrm{a}}$ & $1,1739^{\mathrm{a}}$ & $0,9091^{\mathrm{a}}$ & $0,8000^{\mathrm{a}}$ & $1,2667^{\mathrm{a}}$ \\
\hline
\end{tabular}

Médias na mesma coluna seguidas de letras distintas diferem pelo teste t Student $(\mathrm{p}<0,05)$

${ }^{1}$ CMT - A numeração (0) CMT negativo; (1) CMT positivo +; (2) CMT positivo ++ e (3) CMT positivo +++

O CMT é um teste que estima as células de defesas no leite, sendo que o aumento destas é ocasionado principalmente por microrganismos presentes na glândula mamária. Sabe-se que os maiores índices de mastites, no rebanho leiteiro, estão principalmente associados às inadequadas práticas de manejo e, ao número e à fase de lactação dos animais ordenhados. No entanto, neste trabalho, foi observado que as estações do ano de menores temperaturas e a alta umidade relativa do ar apresentaram significativamente as menores positividades para o teste do CMT. Isto pode estar associado às condições climáticas para o desenvolvimento dos agentes microbianos causadores de mastite. Mesmo em animais acima de 270 dias de lactação, constatou-se que, existe menor positividade para o teste de CMT nas estações climáticas que apresentaram menores temperaturas e menor umidade relativa do ar (Tabela 4).

$\mathrm{Na}$ Tabela 5, verificou-se que os valores médios das contagens demicrorganismos aeróbios mesófilos, Coliformes Totais e Escherichia Coli de amostras de 
leite 'in natura' colhidas durante as quatro estações do ano. A média de Aeróbios Mesófilos, ao longo do ano em ambas as granjas, não excedeu os limites estabelecidos pela IN51. No entanto, as amostras de leite colhidas no outono, na G2 e na primavera da G1 mostraram-se em desacordo com legislação vigente (IN51), que é de no máximo $10.000 \mathrm{UFC} / \mathrm{mL}$. Nero et al. (2004), pesquisando os níveis de contaminação por aeróbios mesófilos em leite cru produzido em quatro importantes Estados produtores de leite no Brasil, demonstraram que $48,57 \%$ das amostras colhidas nestes Estados estavam acima dos limites estabelecidos pela IN51.

Tabela 5. Valores médios das contagens de microrganismos aeróbios mesófilos (AM), Coliformes totais (CT) e Escherichia coli (EC) de amostras de leite, proveniente de granjas leiteiras (G1, G2), no período de 2004/2005.

\begin{tabular}{llcccc}
\hline \multirow{2}{*}{$\begin{array}{l}\text { Classe dos } \\
\text { microrganismos }\end{array}$} & Granjas & \multicolumn{4}{c}{ Média das contagens de microrganismos } \\
\cline { 3 - 6 } & & Verão & Outono & Inverno & Primavera \\
\hline AM & G1 & $3,84 \times 10^{3}$ & $4,67 \times 10^{3}$ & $9,0 \times 10^{3}$ & $12,23 \times 10^{3}$ \\
$(\mathrm{UFC} / \mathrm{mL})$ & $\mathrm{G} 2$ & $8,78 \times 10^{3}$ & $10,64 \times 10^{3}$ & $4,37 \times 10^{3}$ & $5,61 \times 10^{3}$ \\
$\mathrm{CT}$ & $\mathrm{G} 1$ & 3,4 & 10,3 & 3,9 & 1,8 \\
$(\mathrm{NMP} / \mathrm{mL})$ & $\mathrm{G} 2$ & 0,1 & 0,1 & 0,3 & 1 \\
$\mathrm{EC}$ & & 0,6 & 1,9 & 4,8 & 2 \\
$(\mathrm{NMP} / \mathrm{mL})$ & $\mathrm{G} 1$ & 0,3 & 0,9 & 0,2 & 1,1 \\
\hline
\end{tabular}

Para a presença de CT e EC, a IN51 não estabelece limite máximo de contagem para leite cru refrigerado. Estes limites são exigidos apenas para leite pasteurizado. Entre as granjas estudadas, as amostras de leite da G1 apresentaram os maiores valores médios para Coliformes de $30 / 35^{\circ} \mathrm{C}$ e Coliformes $45^{\circ} \mathrm{C}$ durante as estações do ano (Tabela 5). Pelo fato da G 2 apresentar menores contagens ao longo das quatro estações, pode-se dizer que o 'pré-dipping' da G1, utilizando pano mergulhado em solução de Dermisan• (Diaminopropil laurilamina a $30 \%$ ), foi menos eficiente. Fica evidente que altas contagens de Coliformes de $30 / 35^{\circ} \mathrm{C}$ e Coliformes $45^{\circ} \mathrm{C}$ estão ligadas a deficientes práticas de manejo durante a ordenha. Segundo Fagan et al. (2005), a qualidade microbiológica do leite depende fundamentalmente da implantação de boas práticas na produção e menos das condições de infra-estrutura e nível tecnológico da propriedade leiteira.

\section{Conclusões}

As estações do ano e as fases de lactação não mostraram efeitos significativos sobre os parâmetros físico-químicos do leite nas duas granjas leiteiras.

A maior contagem encontrada no final de lactação esteve associada à menor produção de leite e maior descamação do tecido epitelial da glândula mamária.

Os estudos dos efeitos das interações entre as estações do ano e as fases de lactação para determinação do CMT mostraram haver menores incidências de positividade no outono e no inverno.

As contagens de aeróbios mesófilos apresentaram variações nas estações do ano, independentemente do nível de tecnologia na produção de leite. 


\section{Referências}

BRAMLEY,A. J.; CULLOR, J. S.; ERSKINE, R. J.; FOX, I. K.; HARMON, R. J.; HOGAN, J. S.; NICKERSON, S. C.; OLIVER, S. P.; SMITH, K. L.; SORDILLO, I. M. Current concepts of bovine mastitis. 4.ed. Madison: National Mastitis Council, 1996.

BRAMLEY, A. J.; McKINNON, C. H. The microbiology of raw milk. In: ROBINSON, R. K. Dairy microbiology: the microbiology of milk. 2.ed. London: Elsevier Science, 1990. p. 163-207.

BRANDÃO, A. S. P. Restrições econômicas e institucionais à produção de leite na Região Sul. In: RESTRIÇÕES TÉCNICAS, ECONÔMICAS E INSTITUCIONAIS AO DESENVOLVIMENTO DA CADEIA PRODUTIVA DO LEITE NO BRASIL REGIÃO SUL, 1., 1999, Juiz de Fora, MG. Anais... Juiz de Fora: Embrapa Gado de Leite/MCT/CNPQ/PADCT, 1999. p. 27-34.

BRASIL. Ministério da Agricultura. Secretaria Nacional de Defesa Agropecuária. Laboratório Nacional de Referência Animal. Métodos analíticos oficiais para controle de produtos de origem animal e seus ingredientes: II: métodos físicos e químicos. Brasília: Ministério da Agricultura, 1981.

BRASIL. Ministério da Agricultura, Pecuária e Abastecimento. Instrução Normativa $\mathrm{n}^{\circ} 51$, de 20 de setembro de 2002. Aprova os regulamentos técnicos de produção, identidade e qualidade do leite. Diário Oficial [da] República Federativa do Brasil, Brasília, p. 13, Seção 1, 21 set. 2002.

BRASIL. Ministério da Agricultura, Pecuária e Abastecimento. Secretaria de Defesa Agropecuária. Métodos de análises microbiológicas para alimentos. Brasília: MARA, 1991-1992.

CERQUEIRA, M. M. O. P.; SOUZA, M. R.; LEITE, M. O.; BARBOSA, E. M.; ALMEIDA, M. R. Características microbiológicas de leite cru e beneficiado em Belo Horizonte - MG. Arquivo Brasileiro de Medicina Veterinária e Zootecnia, Belo Horizonte, v. 46, n. 6, p. 713-721, 1994.

FAGAN, E. P.; BELOTI, V.; BARROS, M. A. F.; MULLER, E. E.; NERO, L. A.; SANTANA, E. H. W.; MAGNANI, D. F.; VACARELLI, E. R.; SILVA, L. C.; PEREIRA, M. S. Evaluation and implementation of good practices in main points of microbiological contamination in milk production. Semina: Ciências Agrárias, Londrina, v. 26, n. 1, p. 81-90, jan./mar. 2005.

FONSECA, L. F. L.; SANTOS, M. S. Qualidade do leite controle de mastite. São Paulo: Lemos, 2000.
MARTINS, P. C.; YAMAGUCHI, L. C. T. ; ARCURI, P. B.; ARCURI, E. F. O compromisso com a qualidade do leite no Brasil. In: Pagamento por qualidade no Brasil: motivações e obstáculos. Passo Fundo: UPF, 2004.

MATTOS, R. S. W.; PEDROSO, M. A. Influência da nutrição sobre a composição de sólidos totais no leite. In: SIMPÓSIO SOBRE BOVINOCULTURA LEITEIRA, 5., 2005, Piracicaba, SP. Anais... Piracicaba: FEALQ, 2005. p. 103-128.

MILlER, R. H.; PAAPE, M. J.; FULTON, L. A.; SCHUTZ, M. M. The relationship of milk somatic cell count to milk yieds for Holstein heifers after first caving. Journal Dairy Science, Savoy, v. 76, n. 3, p. 728-733, 1993.

NELDER, J.A.; WENDDERBURN, R. W.M. Generalized linear molds. Journal of the Royal Statistical Society: Series A, London, v. 135, n. 3, p. 370-384, 1972.

NERO, L. A.; FRANCO, B. D. G.; MATTOS, M. R.; BELOTI, V.; BARROS, M. A. F.; PINTO, J. P. A. N.; ANDRADE, N. J.; SILVA, W. P. Leite cru de quatro regiões leiteiras brasileiras: perspectivas de atendimento dos requisitos microbiológicos estabelecidos pela instrução normativa ${ }^{\circ}$ 51. In: DÜRR, J. W.; CARVALHO, M. P.; SANTOS, M. V. (Org.). O compromisso com a qualidade do leite no Brasil. Passo Fundo: UPF, 2004, p. 189-194.

PAAPE, M. J.; CAPUCO, A. V.; GUIDRY, A. J. Morphology, function and adaptation of mammary cells in normal and disease states. Journal of Dairy Science, Savoy, v. 73, n. 2, p. 1-17, 1995.

PADILHA, M. R. F.; FERNADEZ, Z. F. Avaliação higiênico-sanitária do leite "C" comercializado no Recife - PE. Higiene Alimentar, São Paulo, v. 13, n. 61, p. 105109, 1999.

PHILPOT, W. N.; NICKERSON, S. C. Mastitis: counter attack. Naperville: Babson Bros, 1991.

SANTOS, E. C.; XAVIER, A. T. V.; PASSOS, L. A. S. Aparente deflexão sazonal de alguns constituintes do leite no início da primavera. Revista do Instituto de Laticínios Cândido Tostes, Juiz de Fora, v. 36, n. 215, p. 9-15, 1981.

SILVEIRA, N. V. V.; SAKUMA, H.; DUARTE, E. L. Avaliaçãodascondições físico-químicasemicrobiológicas do leite pasteurizado consumido na cidade de São Paulo. Revista do Instituto Adolfo Lutz, São Paulo, v. 49, n. 1, p. 19-22, 1989.

SOLER, C. P. A.; DE PAZ, M.; NUÑEZ, M. The microbiological quality of milk produced in the Baleric 
Islands. International Dairy Journal, Brussels, v. 5, p. 69-74, 1995.

STATISTICAL ANALYSIS SYSTEM - SAS. Technical report P-229. SAS/STAT Software: changes and enhancements: release 6.07. Cary: SAS, 1992.

THIERS, F. O. Correlação entre contagem direta de células somáticas e o teste de "California Mastitis test" no leite de vacas. Napgama, São Paulo, v. 2, n. 4, p. 9-12, 1999.
TRONCO, V. M. Manual para inspeção da qualidade do leite. Santa Maria: Ed. da Universidade Federal de Santa Maria, 2003.

WOLTER, R. Alimentation de la vache laitière. 3.ed. Paris: France Agricole, 1997. p. 187-214. 